\title{
Does screening for stage I lung cancer improve survival in a high-risk population?
}

\section{Ugo Pastorino}

Nature Clinical Practice Oncology (2007) 4: 218-219 [doi:10.1038/ncponc0766]

doi:10.1038/ncponc0793

\section{CORRIGENDUM}

In this issue of Nature Clinical Practice Oncology the Practice Point by Ugo Pastorino contains a reference supplied by the author for an article that had not yet been published but which was not cited correctly as being 'in press'.

The article was still under embargo when the Practice Point appeared as an advance online publication. When the embargo was lifted on March 6 2007, the title and page numbers in the citation were revealed as having been altered from those supplied.

The correct citation should read "Bach PB et al. (2007) Computed tomography screening and lung cancer outcomes. JAMA 297: 953-961".

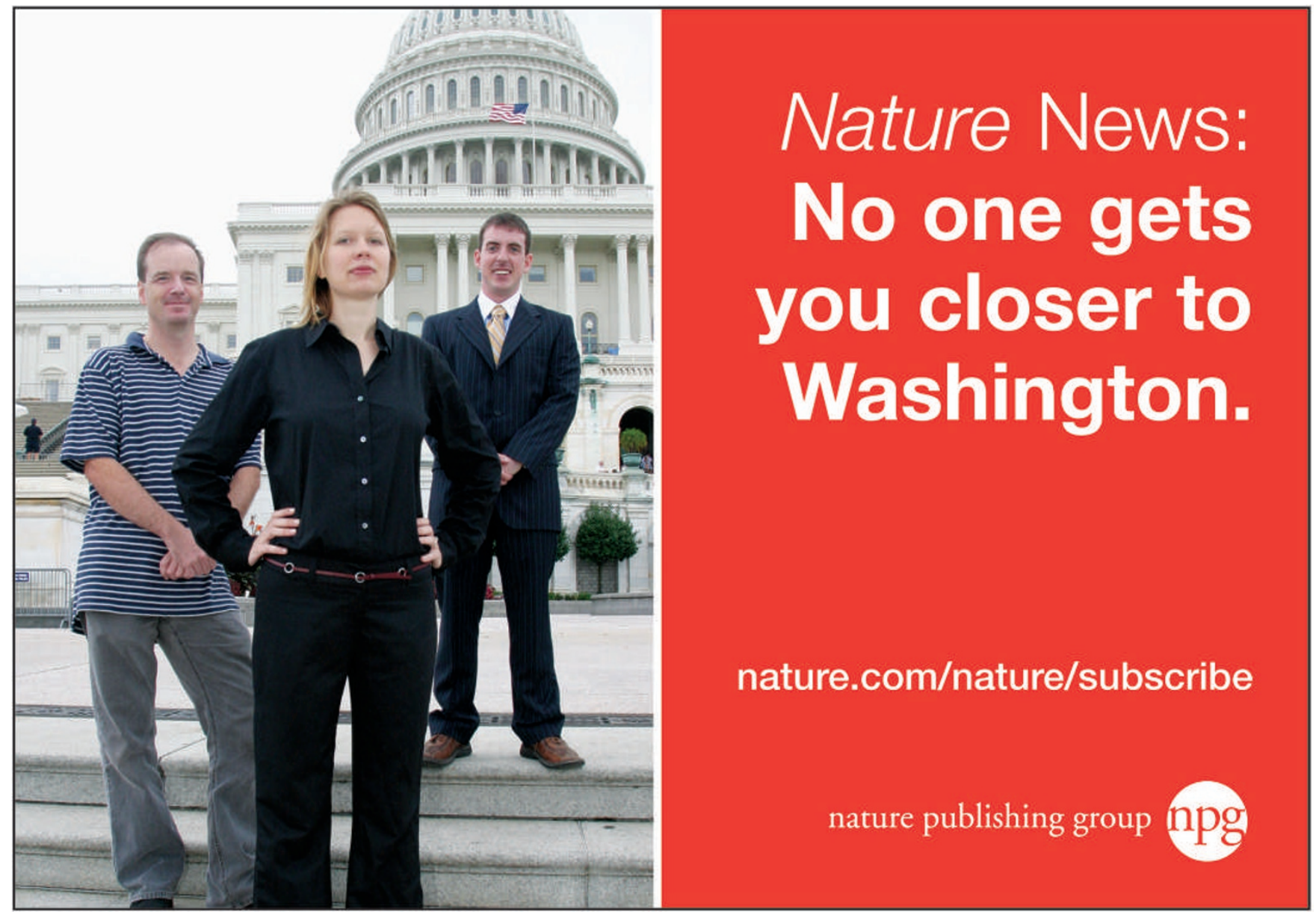

